\title{
Control Strategies for MMC Using Cells with Power Transfer Capability
}

\author{
Mario López, Fernando Briz, Alberto Zapico, Alberto Rodríguez and David Diaz-Reigosa \\ Department of Electrical Engineering, University of Oviedo, Spain \\ lopezmario@uniovi.es
}

\begin{abstract}
Conventional MMCs use cells which typically consist of a half-bridge and a capacitor. Due to their limited energy storage capability, the net power balance of the cells is zero (neglecting losses), the MMC therefore realizing a bidirectional power transfer between its DC and AC ports. It is possible however to provide the MMC with the capability to transfer power at the cell level. The use of such cells opens new functionalities and uses for the MMC, including integration at the cell level of distributed energy storage (e.g. batteries), low-voltage/low power sources/loads, and its operation as a multiport power converter, combining high and low voltage $\mathrm{AC}$ and $\mathrm{DC}$ ports. Existing control strategies for MMCs assume that all the cells have an identical design and operate identically. However, use of cells with power transfer capability can result in imbalances in their operation, provided that not all the cells transfer power, or that they do not transfer the same amount of power.

This paper addresses the design and control of MMCs using cells with power transfer capability, with special focus on the design of suitable control strategies and on the definition of their limits of operation.
\end{abstract}

Index Terms-Modular Multilevel Converter, MMC, Multiport Power Converters, Solid State Transformer

\section{INTRODUCTION}

Reducing the dependence on conventional fossil fuels has become a priority for industrialized countries due to environmental concerns, limited resources and the progressive increase of their cost. This scenario has pushed the penetration of renewable energies in the existing transmission system. However, massive integration of renewable energy into the existing and future grids poses major challenges, as a significant part of the installed capacity will be connected to the distribution levels [1]. Innovative solutions based on high-power, high-voltage electronic power converters, like High Voltage Direct Current (HVDC) and Flexible AC Transmission Systems (FACTS) have the potential to cope with these challenges, also providing to the power system operator functionalities such as power flow control, power quality improvement and reduction of transmission losses among others [2].

Multilevel converters are well suited for medium-high voltage/power ranges which are required for electronic power converters connected to medium voltage electrical grids [3]. Among these, the Modular Multilevel Converters (MMCs)

\footnotetext{
This work was supported in part by the Research, Technological Development and Innovation Programs of the Spanish Ministries of Science and Innovation and of Economy and Competitiveness, under grants MICINN10-CSD2009-00046 and MINECO-13-ENE2013-48727-C2-1-R, and by the European Commission FP7 Large Project NMP3-LA-2013-604057, under grant UE-14-SPEED-604057.
}

appear as a promising topology for applications requiring a high voltage DC port (e.g. HVDC), being a hot research topic nowadays. MMC was first introduced one decade ago [4]-[6]. It realizes a bidirectional DC/AC power conversion, sharing the advantages of other multilevel converters: reduced size of filters due to better output voltage wave shape; lower switching losses due to the reduced switching frequency; capability of withstanding large terminal voltages using relatively low voltage power devices. Additionally, it provides attractive features compared to other multilevel topologies, such as modularity (identical cells are piled-up to increase the voltage) and consequently easy scalability, and distributed energy storage, therefore eliminating the need of a bulk DC capacitor [4]-[7].

Conventional MMC use cells consisting of a half-bridge and a capacitor. Control and modulation strategies developed for MMCs are aimed to balance the power between the AC and DC ports, which is needed to maintain the average voltage of the cells capacitors at its target value. This is done by controlling the circulating current either explicitly [8]-[13] or indirectly (i.e direct modulation) [14]-[16]. Balancing of the cell capacitor voltages is also required [4]-[16]. Due to the fact that the cells have a limited energy storage capability, the net power balance for each cell is zero (neglecting losses), $\mathrm{AC}$ and DC powers being therefore equal to each other. It is possible however to transfer (absorb or deliver) power through the MMC cells. This would provide the MMC with new potential features, including distributed energy storage [17]; integration of distributed energy resources (DER) at the cell level; multiport multilevel power converters combining the medium/high voltage $\mathrm{DC}$ and $\mathrm{AC}$ ports of the MMC with low voltage DC and AC ports. Another potential application being Solid State Transformers (SST) [19]-[21].

This paper addresses the design and control of MMCs using cells with power transfer capability. The paper is organized as follows. Basic concepts and power balance requirements of conventional MMCs are presented in Section II. Section III extends the analysis to the case of MMCs using cells with power transfer capability. Section IV presents MMC configurations using cells with power transfer capability. Limits of operation and control strategies are presented in Sections V and VI respectively, simulation and experimental results being presented in Sections VII and VIII. Finally, conclusions are presented in Section IX. 


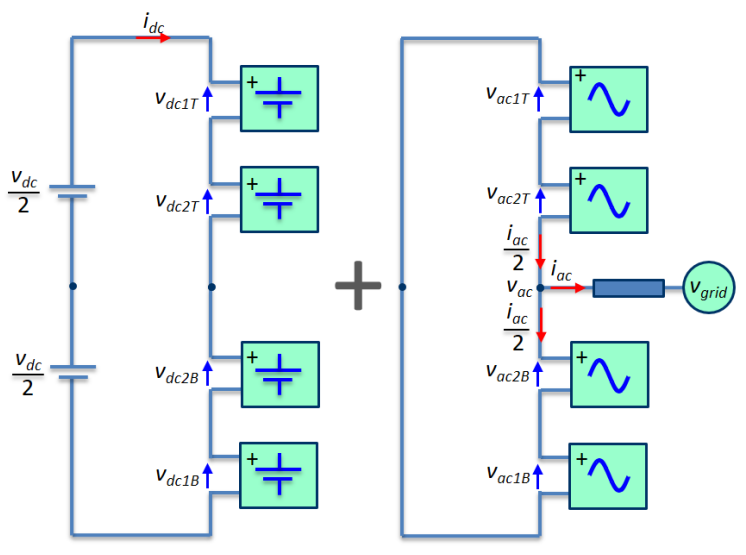

Fig. 1. DC (left) and AC (right) subcircuits of the MMC.

\section{MMC MOdel AND POWER BALANCE}

MMCs realize a power transfer between an $\mathrm{AC}$ and a DC port. It is useful for analysis purposes to separate the MMC into its DC and AC subcircuits, as shown in Fig. 1. The discussion following assumes two cells per arm $(\mathrm{N}=2)$, without loss of generality. Also the voltage drop in the arm inductors is neglected for simplicity. For the case of a three-phase MMC, complex vector notation can be used to represent the $\mathrm{AC}$ variables, such as voltage (1) and current vectors (2). For the DC subcircuit (Fig. 1-left), the cells are series connected, the resulting voltage being equal to the DC voltage of the MMC (3). On the contrary, for the AC voltage subcircuit (Fig. 1-right), top and bottom arms are parallel connected, the corresponding AC cell voltages being (4) and (5) respectively. Consequently, AC current equally splits between the two arms. The resulting top and bottom arm currents are (6) and (7), the circulating current being (8). For the sake of simplicity, it is assumed that the circulating current does not contain harmonics [13][18], being therefore equal to the DC current.

$$
\begin{gathered}
v_{a c}=\frac{2}{3}\left(v_{u}+v_{v} e^{j 2 \pi / 3}+v_{w} e^{j 4 \pi / 3}\right) \\
i_{a c}=\frac{2}{3}\left(i_{u}+i_{v} e^{j 2 \pi / 3}+i_{w} e^{j 4 \pi / 3}\right) \\
v_{d c n T}=v_{d c n B}=\frac{v_{d c}}{2 N} \\
v_{a c n T}=\frac{v_{a c T}}{N}=\frac{-v_{a c}}{N} ; n=1,2 \\
v_{a c n B}=\frac{v_{a c B}}{N}=\frac{v_{a c}}{N} ; n=1,2 \\
i_{T}=i_{d c}+\frac{i_{a c}}{2} \\
i_{B}=i_{d c}-\frac{i_{a c}}{2} \\
i_{c}=\frac{i_{T}+i_{B}}{2}=i_{d c}
\end{gathered}
$$

Since conventional cells have limited energy storage capability, the power in the DC port has to be equal to the active power in the AC port (9). The DC current is controlled to match the DC and AC powers (10)-(11). In addition, cell capacitor voltages must be kept at their target value, e.g. using sorting

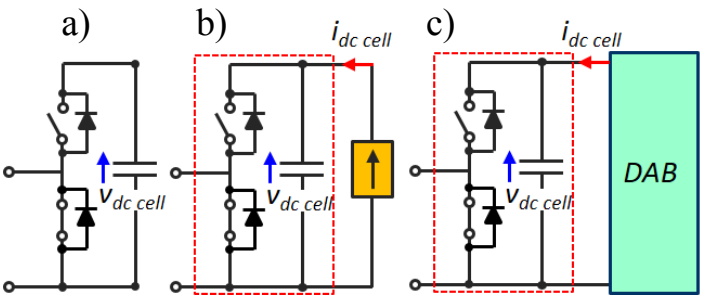

Fig. 2. a) Conventional half-bridge cell with a capacitor in the DC link; b) cell including a current source; c) cell using a DAB.

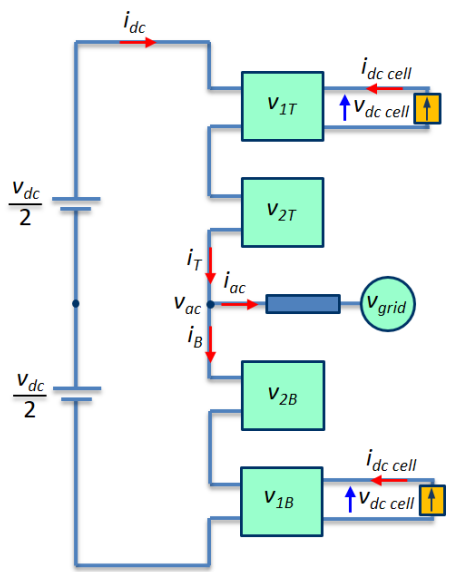

Fig. 3. MMC including cells with power transfer capability in all the three phases. Same number of cells in top and bottom arms transfer power.

algorithms [12]-[16] or individual balancing [8]-[10].

$$
\begin{gathered}
P_{d c}=v_{d c} \cdot i_{d c}=P_{a c}=\operatorname{Re}\left(v_{a c} \cdot i_{a c}{ }^{*}\right) \\
P_{d c n T}=P_{d c n B}=\frac{v_{d c}}{2 N} i_{d c}=\frac{v_{d c}}{4} i_{d c} ; n=1,2 \\
P_{a c n T}=P_{a c n B}=\operatorname{Re}\left(\frac{v_{a c T}}{N} \frac{i_{a c}{ }^{*}}{2}\right)=\operatorname{Re}\left(\frac{v_{a c B}}{N} \frac{-i_{a c}{ }^{*}}{2}\right)
\end{gathered}
$$

\section{Power Balance in MMCs Using Cells with POWER TRANSFER CAPABILITY}

As already mentioned, it is possible for the MMC to transfer power at the cell level. Assumed that the cells are adequately controlled to maintain the capacitor voltage $v_{d c c e l l}$ constant, connection of a power source to the cell can be modeled as a current source connected to the cell capacitor (Fig. 2 b)[19]. In a practical implementation, galvanic isolation between the cell capacitor and the power source will be normally needed. A current controlled dual active bridge (DAB) could be used for this purpose (Fig. 2-c) [17], [19]-[21]. In the discussion following, it is assumed that cells $1 T$ and $1 B$ in all the threephases transfer power (see Fig.3). Due to the symmetry among phases and between the top and bottom arms, injection of power at the cell level will not produce any type of harmonics or imbalances in the DC and AC voltages of the MMC.[19].

The power balance equation of the MMC including cells with power transfer capability is given by (12), where $M$ stands for the number of cells transferring power. The power balance equations for the individual cells are (13)-(16). It is noted that the power transferred by cells $2 T$ and $2 B$ is zero. 


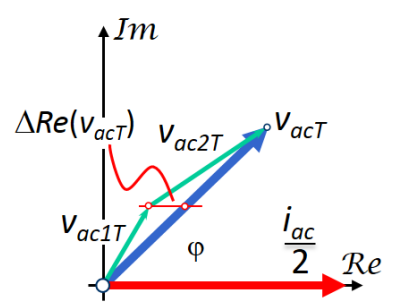

Fig. 4. AC voltage unbalance varying only the real component of the cell voltages $\left(\operatorname{Im}\left(v_{a c 1 T}\right)=\operatorname{Im}\left(v_{a c 2 T}\right)\right)$.

$$
\begin{gathered}
P_{d c}+P_{a c}+M \cdot P_{\text {cell }}=0 \\
P_{\text {cell } 1 T}=v_{d c 1 T} \cdot i_{d c}+\operatorname{Re}\left(v_{a c 1 T} \frac{i_{a c}{ }^{*}}{2}\right)=v_{d c c e l l} \cdot i_{d c c e l l} \\
P_{c e l l 2 T}=v_{d c 2 T} \cdot i_{d c}+\operatorname{Re}\left(v_{a c 2 T} \frac{i_{a c}{ }^{*}}{2}\right)=0 \\
P_{c e l l 1 B}=v_{d c 1 B} \cdot i_{d c}+\operatorname{Re}\left(v_{a c 1 B} \frac{-i_{a c}{ }^{*}}{2}\right)=v_{d c c e l l} \cdot i_{d c c e l l} \\
P_{c e l l 2 B}=v_{d c 2 B} \cdot i_{d c}+\operatorname{Re}\left(v_{a c 2 B} \frac{-i_{a c}{ }^{*}}{2}\right)=0
\end{gathered}
$$

Differences in the power balance equation of the cells will imply asymmetries in their terminal voltages and/or currents. Since the DC current is common to all the cells, the asymmetries need to occur in the cell DC voltages $v_{d c n T}, v_{d c n B}$, AC voltages $v_{a c n T}, v_{a c n B}$, or in the AC component of the arm currents $i_{T}$ and $i_{B}$. In the discussion following, it is assumed that the asymmetries occur in the cell voltages. The DC and $\mathrm{AC}$ voltages equations can be rewritten as (17)-(18) and (19)(20) respectively, $\Delta v_{d c}$ and $\Delta R e\left(v_{a c}\right)$ accounting for the DC and $\mathrm{AC}$ voltage imbalance among the cells in each arm.

$$
\begin{gathered}
v_{d c 1 T}=\frac{v_{d c}}{4}+\Delta v_{d c}=v_{d c 1 B} \\
v_{d c 2 T}=\frac{v_{d c}}{4}-\Delta v_{d c}=v_{d c 2 B} \\
v_{a c 1 T}=\frac{v_{a c T}}{2}+\Delta R e\left(v_{a c}\right)=v_{a c 1 B} \\
v_{a c 2 T}=\frac{v_{a c T}}{2}-\Delta \operatorname{Re}\left(v_{a c}\right)=v_{a c 2 B}
\end{gathered}
$$

It is noted that since the $\mathrm{AC}$ voltage $v_{a c}$ is a complex vector, $\Delta R e\left(v_{a c}\right)$ is a complex vector too. In the discussion following, the real axis is defined to be aligned with the AC current vector (see Fig. 4). By doing this, $\Delta R e\left(v_{a c}\right)$ only affects to the active power transferred by the cells [19]. It is finally noted that irrespective of the imbalances among cells, the overall DC and $\mathrm{AC}$ voltages of the MMC (21) and (22) remain unchanged.

$$
\begin{aligned}
& v_{d c 1 T}+v_{d c 2 T}+v_{d c 1 B}+v_{d c 2 B}=v_{d c} \\
& v_{a c 1 T}+v_{a c 2 T}=v_{a c 1 B}+v_{a c 2 B}=v_{a c}
\end{aligned}
$$

Using (13)-(20), it is possible to analyze the effects of $\Delta v_{d c}$ and $\Delta R e\left(v_{a c}\right)$ on the power transferred by the cells (13)-(16) and on the MMC power balance (12). Fig. 5-a shows the power
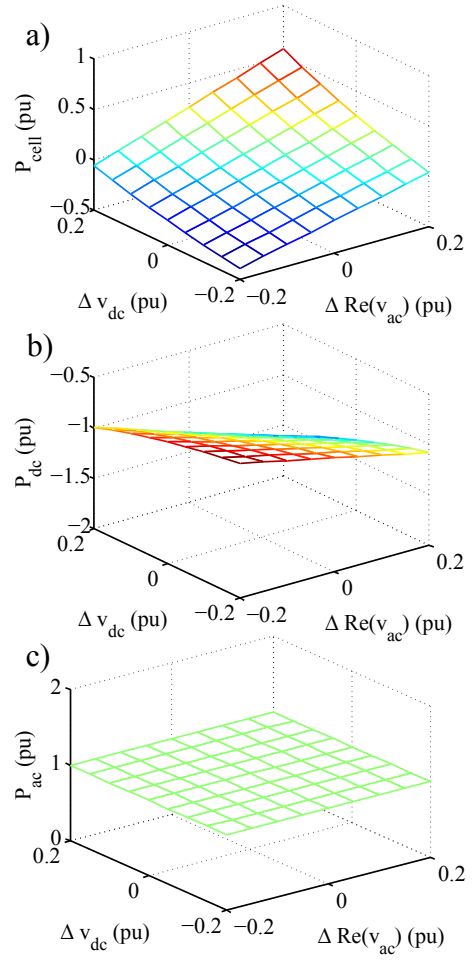

Fig. 5. a) Cell power $P_{c e l l}$; b) DC port power $P_{d c}$; c) AC port power $P_{a c}$; as a function of $\Delta v_{d c}$ and $\Delta R e\left(v_{a c}\right)$, for constant AC power

transferred by cells $1 T$ and $1 B$ vs. $\Delta v_{d c}$ and $\Delta R e\left(v_{a c}\right)$, for constant AC power $P_{a c}$ (Fig. 5-c). The power transferred by the cells is seen to affect to the power at the DC port of the MMC, (Fig. 5-b), (12) holding in all the cases. Power transferred by cells $2 T$ and $2 B$ is always zero.

\section{A. MMC Power Balance Constraints}

MMCs including cells with power transfer capability must satisfy the power balance equation (12). However, there are constraints regarding the way in which the AC, DC and cell powers can be combined in (12) which need to be considered. Table I summarizes the different modes of operation and their feasibility for the particular case shown in Fig. 3 and Fig.6-d. It is possible to transfer all the cell power $P_{\text {cell }}$ to the AC port (Mode 2). On the contrary, transferring the power from the cells to the DC port is only possible if there is reactive power in the AC port (Mode 4). It must be remarked that Mode 3 is not possible for the topology in Fig.6-d, but becomes feasible for the fully symmetric topology in Fig.6-e.

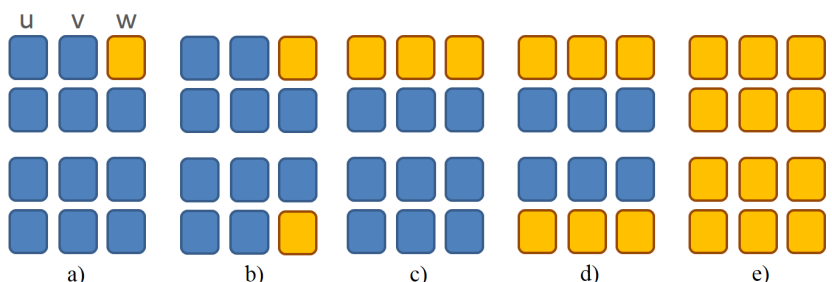

Fig. 6. ${ }^{\text {a) }}$ MMC configurations including cells with power transfer capability. Cells in light color transfer power, cells in dark color do not. a) asymmetric phases and arms; b) symmetric arms, asymmetric phases; c) asymmetric top and bottom arms; d) symmetric top and bottom arms, asymmetric cells; e) fully symmetric 
TABLE I

Power Transfer Modes (TOPOlOGy IN Fig.6-D)

\begin{tabular}{c|c|c|c|c|c}
\hline Mode & $P_{\text {cell }}$ & $P_{d c}$ & $P_{a c}$ & $Q_{a c}$ & Feasible \\
\hline 1 & 0 & $\neq 0$ & $\neq 0$ & - & Yes $\left(P_{d c}+P_{a c}=0\right)$ \\
\hline 2 & $\neq 0$ & 0 & $\neq 0$ & - & Yes $\left(M P_{c e l l}+P_{a c}=0\right)$ \\
\hline 3 & $\neq 0$ & $\neq 0$ & 0 & 0 & Not feasible \\
\hline 4 & $\neq 0$ & $\neq 0$ & 0 & $\neq 0$ & Yes $\left(M P_{c e l l}+P_{d c}=0\right)$ \\
\hline 5 & $\neq 0$ & $\neq 0$ & $\neq 0$ & - & Yes $\left(P_{d c}+P_{a c}+M \cdot P_{c e l l}=0\right)$ \\
\hline
\end{tabular}

TABLE II

TYPES OF ASYMMETRY AND EFFECTS ON THE AC PORT DEPENDING ON THE APPLIED CELL VOLTAGE IMBALANCE

\begin{tabular}{c|c|c}
\hline Type of asymmetry & Voltage imbalance & Effect on MMC operation \\
\hline \multirow{2}{*}{ Fig.6-a) } & $\Delta v_{d c}$ & DC zero sequence in the AC port voltage \\
\cline { 2 - 3 } & $\Delta R e\left(v_{a c}\right)$ & Unfeasible \\
\hline \multirow{2}{*}{ Fig.6-b) } & $\Delta v_{d c}$ & DC zero sequence in the AC port voltage \\
\cline { 2 - 3 } & $\Delta R e\left(v_{a c}\right)$ & Different $i_{c x}$ within phases \\
\hline \multirow{2}{*}{ Fig.6-c) } & $\Delta v_{d c}$ & DC zero sequence in the AC port voltage \\
\cline { 2 - 3 } & $\Delta R e\left(v_{a c}\right)$ & Unfeasible \\
\hline \multirow{2}{*}{ Fig.6-d) } & $\Delta v_{d c}$ & No effect \\
\cline { 2 - 3 } & $\Delta R e\left(v_{a c}\right)$ & No effect \\
\hline \multirow{2}{*}{ Fig.6-e) } & $\Delta v_{d c}=0$ & No effect \\
\cline { 2 - 3 } & $\Delta R e\left(v_{a c}\right)=0$ & No effect \\
\hline
\end{tabular}

\section{MMC Configurations Using Cells with Power TRANSFER CAPABILITY}

In the MMC shown in Fig. 3, the same number of cells in the top and bottom arms and in all the three phases transfer power, i.e. phases and arms are symmetric. While this is the case analyzed in detail in this paper, other options exist, they are discussed briefly in this section. Depending on the number and location of the cells transferring power (see Fig.6), different types of asymmetries (imbalances) among cells, and consequently among arms or legs, can occur. In all the cases, all the cells in each leg of the MMC must have the same DC current. It is also assumed that the AC current equally splits among the top and bottom arms of each leg. Accordingly, all the cells must have the same DC and AC currents. Consequently, producing asymmetries in the power transferred by the cells will produce asymmetries in their DC and/or AC voltages (17)-(20).

Imbalances among phases and arms (Fig.6-a) will result in different DC voltages for the cells in phase $w$, eventually resulting in a $\mathrm{DC}$ zero sequence voltage in the $\mathrm{AC}$ voltage vector $v_{a c}$. Unbalancing the cells $\mathrm{AC}$ voltages is not possible, since both top and bottom must generate the same AC voltage $v_{a c}$ and the currents are the same. The case shown in Fig.6-b, produces DC zero sequence voltage in the AC port. Unbalancing the AC cell voltages is also feasible, but will result in unbalances among phases in the circulating currents $i_{c x}$. Fig.6$\mathrm{c}$ produces imbalances between the DC voltage for the top and bottom arms of all the three phases, and consequently a DC zero sequence component in the $\mathrm{AC}$ voltage $v_{a c}$. Unbalancing the cell AC voltages is not possible. In the case shown in Fig.6-d, top and bottom arms are symmetric, but there are imbalances among the cells in each arm. Cells DC and/or AC voltages can be unbalanced in this case, but with no impact on the AC voltage of the MMC $v_{a c}$. Finally, Fig.6-e does not produce any type of unbalance either in the MMC voltages or in the arm voltages. Table II summarizes the different types of asymmetries and the effects on the MMC/cells behavior.

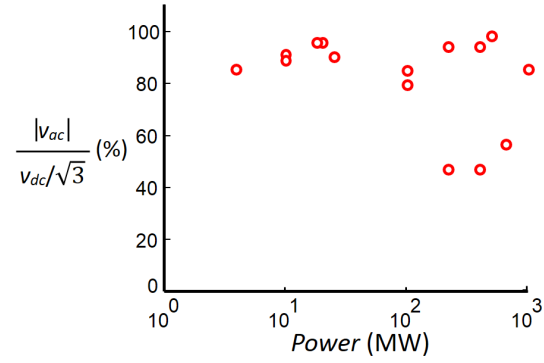

Fig. 7. AC/DC voltage ratio $R$ vs. power in existing (or in progess) MMC.

\section{Limits of Operation of Cells with Power TRANSFER CAPABILITY}

\section{A. Cells and MMC voltage limits \& cell power transfer limits}

It has been shown in Section III that power transferred by cells is controlled by adequate selection of the voltage imbalance, the amount of power being transferred being proportional to $\left|\Delta v_{d c}\right|$ and $\left|\Delta R e\left(v_{a c}\right)\right|$. The maximum power that can be transferred will depend therefore on the maximum voltage imbalance that can be produced. Consequently, cells and MMC voltage restrictions need to be considered.

Cells lower and upper voltage limits for half bridge cells are 0 and $v_{d c}$ cell $=v_{d c} / N$ respectively. As for the MMC, the peak value of the $\mathrm{AC}$ voltage $v_{a c}$ is limited to $-v_{d c} / 2$ and $v_{d c} / 2$. The ratio between the MMC AC and DC port voltages (23) will be therefore a key figure. It is noted that the line impedance voltage drop was neglected in this equation for simplicity. Triplen harmonic injection is also considered.

$$
R=\frac{\sqrt{3} \cdot\left|v_{a c}\right|}{v_{d c}}
$$

$R$ indicates the voltage margin which is available to produce voltage imbalances among cells. For $R=1$, all the cells operate at their voltage limit, no voltage imbalance being therefore possible. Values of $R<1$ mean that a voltage margin exists to introduce imbalances among cells voltages. For reference, Fig. 7 shows examples of the $R$ ratio reported for already installed (or under development) MMC.

The maximum power that cells can transfer will depend on:

- The voltage margin $R$

- The AC port power (active and reactive)

- The number of cells transferring power $M$

Fig. 8-a) and Fig. 8-b) schematically show the resulting DC and AC cell voltages, considering the imbalance limits $\Delta v_{d c \max }$ and $\Delta R e\left(v_{a c} \max \right)$, which are function of the voltage margin $R$. Subindex $1 T$ and $1 B$ account for all the cells in the top and bottom arms transferring power, and $2 T$ and $2 B$ for cells which do not transfer power.

It is finally noted that the sign of $\Delta v_{d c}$ and $\Delta R e\left(v_{a c}\right)$ need to be selected according to the sign of the cell power (injected or drawn) and the sign of the AC power, as shown in Table III. For $P_{a c}>0$, increasing the power transferred by the cell (i.e. more negative cell power, $\downarrow$ ) can be achieved either decreasing $\Delta v_{d c}(\downarrow)$ or increasing $\Delta R e\left(v_{a c}\right)(\uparrow)$. The opposite behavior occurs for $P_{a c}<0$. Sign $(+)$ in brackets stands for the same variation direction as $P_{\text {cell }}$, the opposite represented by ( - ). 
a)
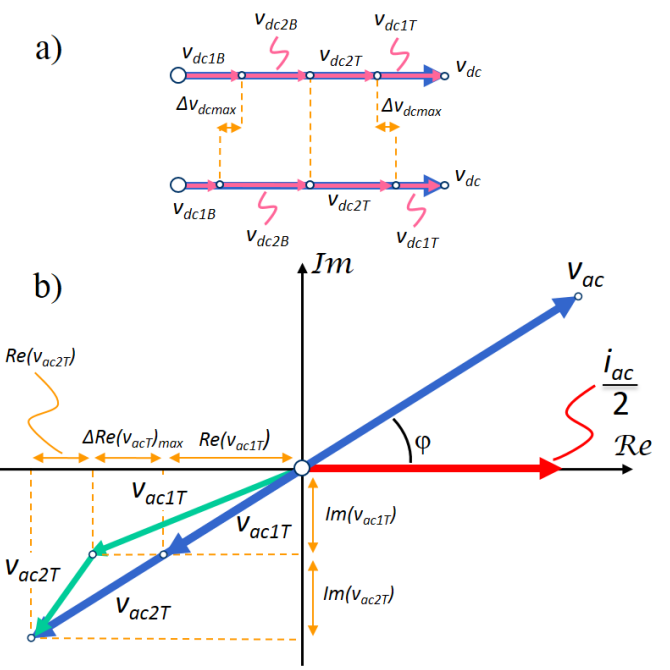

Fig. 8. Voltage imbalance limits for $P_{a c}>0$. a- DC cell voltage imbalance. b- AC cell voltage imbalance (real axis aligned with the AC current vector)

TABLE III

Cell Power vs. Voltage Imbalance

\begin{tabular}{|c|c|c|}
\hline AC Power & \multicolumn{2}{|c|}{ Voltage imbalance } \\
\hline$P_{a c}$ & $\frac{\Delta P_{\text {cell }}}{\Delta v_{d c}}$ & $\frac{\Delta P_{\text {cell }}}{\Delta R e\left(v_{a c}\right)}$ \\
\hline$>0$ & $(+)$ & $(-)$ \\
$<0$ & $(-)$ & $(+)$ \\
\hline
\end{tabular}

\section{B. Maximum power transfer using AC voltage imbalance}

This subsection discusses the maximum power can be transferred by the cells when the voltage margin $R$ is used exclusively to produce an AC voltage imbalance. Since the daxis is defined to be aligned with the AC current (see Fig. 8), the $\mathrm{d}$-axis component of the voltage vector will be responsible of the active power and the q-axis voltage of the reactive power. The discussion following is particularized for the top arm voltages, identical conclusions are reached for the bottom arm voltages. The maximum d-axis voltage that any cell can produce is given by (24), $v_{a c T q}$ being the q-axis voltage needed to supply the requested $\mathrm{AC}$ reactive power.

$$
v_{a c T d \max }=\sqrt{\left(\frac{v_{d c}}{2 N}\right)^{2}-\left(\frac{v_{a c T q}}{N}\right)^{2}}
$$

The actual AC voltage for each particular cell will depend on the sign of $P_{a c}$. For $P_{a c}>0$, the maximum AC voltage of the cells injecting power is (24). The $M$ cells injecting power account for a total voltage $v_{a c 1 T d}(25)$. The $N-M$ cells which do not inject power account therefore for a total voltage of $v_{a c 2 T d}(26)$. The overall AC voltage vector of the $M$ cells injecting and the $N-M$ cells which do not inject is given (27) and (28) respectively.

$$
\begin{gathered}
v_{a c 1 T d}=M \cdot v_{a c T d \max } \\
v_{a c 2 T d}=v_{a c T d}-v_{a c 1 T d} \\
v_{a c 1 T}=v_{a c 1 T d}+j \frac{v_{a c T q}}{N} \\
v_{a c 2 T}=v_{a c 2 T d}+j \frac{v_{a c T q}}{N}
\end{gathered}
$$

Analogously, (29)-(32) hold for the case of $P_{a c}<0$.

$$
\begin{gathered}
v_{a c 2 T d}=(N-M) \cdot v_{a c T d \max } \\
v_{a c 1 T d}=v_{a c T d}-v_{a c 2 T d} \\
v_{a c 1 T}=v_{a c 1 T d}+j \frac{v_{a c T q}}{N} \\
v_{a c 2 T}=v_{a c 2 T d}+j \frac{v_{a c T q}}{N}
\end{gathered}
$$

In both cases, (33) and (34) hold.

$$
\begin{gathered}
v_{d c 1 T}=\frac{v_{d c}}{2 N} \cdot M \\
v_{d c 2 T}=\frac{v_{d c}}{2 N} \cdot(N-M)
\end{gathered}
$$

The maximum power that the cells can transfer is (35).

$$
P_{\text {cell max }}=3\left(\frac{v_{d c 1 T}}{v_{d c 2 T}} v_{a c 2 T d} \frac{i_{a c}}{2}+v_{a c 1 T d} \frac{i_{a c}}{2}\right)
$$

Finally, it is possible to express the d-axis component of the $\mathrm{AC}$ voltage for non-injecting (2T) and injecting (1T) cells as a function the DC current $i_{d c}, \mathrm{AC}$ voltage $v_{a c}$ and $\mathrm{AC}$ current $i_{a c}$ (36)-(37). Alternatively, $v_{a c 2 T d}$ and $v_{a c 1 T d}$ can also be written as a function of the apparent power, load angle and power injected (or drained) by the cells.

$$
\begin{gathered}
v_{a c 2 T d}=-\frac{2}{3 N} \frac{v_{d c}(N-M) i_{d c}}{i_{a c}} \\
v_{a c 1 T d}=v_{a c T d}-v_{a c 2 T d}
\end{gathered}
$$

\section{Maximum power transfer using DC voltage imbalance}

This subsection discusses the maximum power that can be transferred by the cells when all the available voltage margin $R$ is used to produce a DC voltage imbalance. The maximum and minimum DC voltage that a conventional half-bridge cell can withstand are (38)-(39).

$$
\begin{gathered}
v_{d c T \text { max }}=\frac{v_{d c}}{N}-\frac{\left|v_{a c T}\right|}{N} \\
v_{d c T \text { min }}=\frac{\left|v_{a c T}\right|}{N}
\end{gathered}
$$

Table IV shows the voltage for the injecting and noninjecting cells $v_{d c 1 T}$ and $v_{d c 2 T}$, as a function of the AC power sign and of the number of cells injecting.

TABLE IV

DC VOLTAGE IMBALANCE

\begin{tabular}{c|c|c|c}
\hline$P_{a c}$ & $M$ vs. $N$ & $v_{d c 1 T}$ & $v_{d c 2 T}$ \\
\hline$>0$ & $M>(N-M)$ & $\frac{v_{d c}}{2}-v_{d c 2 T}$ & $v_{d c T \max }(N-M)$ \\
\hline$<0$ & $M>(N-M)$ & $\frac{v_{d c}}{2}-v_{d c 2 T}$ & $v_{d c T \min }(N-M)$ \\
\hline$>0$ & $M<(N-M)$ & $v_{d c T \min } M$ & $\frac{v_{d c}}{2}-v_{d c 1 T}$ \\
\hline$<0$ & $M<(N-M)$ & $v_{d c T \max } M$ & $\frac{v_{d c}}{2}-v_{d c 1 T}$ \\
\hline
\end{tabular}

AC voltage sharing between the injecting and non-injecting cells in all the cases is given by (40) and (41).

$$
\begin{gathered}
v_{a c 1 T}=\frac{v_{a c T}}{N} \cdot M \\
v_{a c 2 T}=\frac{v_{a c T}}{N} \cdot(N-M)
\end{gathered}
$$


Maximum power that can be transferred by the cells is obtained from (35). As for the AC voltage imbalance case, the DC voltage for non-injecting and injecting cells can be expressed as a function the DC current $i_{d c}$, AC voltage $v_{a c}$ and AC current $i_{a c}$, (42), (43).

$$
\begin{aligned}
& v_{d c 2 T}=-\frac{3}{4} \frac{v_{a c 2 T d} \cdot i_{a c}}{i_{d c}} \\
& v_{d c 1 T}=-\frac{v_{d c}}{2}-v_{d c 2 T}
\end{aligned}
$$

\section{Numerical analysis}

Fig. 9 shows the maximum power that can be transferred by the cells, $P_{\text {cell max }}$, as a function of the apparent power $S_{a c}$ and the AC load angle for three values of $M$, for the case of $\mathrm{DC}$ and $\mathrm{AC}$ voltage unbalances.

Fig. 9-left shows maximum power when only a DC cell voltage imbalance is used. Peaks occur for the case of pure active power ( 0 and 180 degrees) in the AC port. In these cases, the ratio $i_{d c}$ vs. $\left|i_{a c}\right|$ is maximum, so is the power transfer resulting from imbalances in the cell DC voltage. The maximum power capability occurs for a purely negative active power. In this case, the MMC AC voltage decreases, increasing the voltage margin. On the contrary, it is not possible to transfer cell power if purely reactive power exists in the AC port (90 and 270 degress). In these cases $i_{d c}=0$, imbalances in the cell DC voltage not producing a power transfer.

It is seen from Fig. 9-left-a) and b) that increasing the number of active cells $M$ increases the power transferred. However, there is a limit for this, which occurs when the number of cells injecting equals the number of cells which do not inject (i.e. $M=N / 2$ ). Increasing $\mathrm{M}$ beyond this limit does not increase the overall power transfer (see Fig. 9-left-b) and c)). This is due to the fact that the overall DC port voltage $v_{d c}$ has to be shared by the cells injecting power.

Fig. 9-right shows the power transferred by the cells when only a AC cell voltage imbalance is used. Unlike the previous case, peaks of the power transfer occur for purely AC reactive power (90 and 270 degrees). The reason is that the voltage margin needed to produce the voltage unbalance increases when there is no active power. It is noted that in this case, the power transferred increases proportionally to the number of cells transferring power $M$.

It is finally noted that for any value of the apparent power and load angle, AC voltage imbalances (Fig. 9-right) allow to transfer more power than DC voltage imbalances (Fig. 9-left).

\section{Control Strategies for MMCs Using Cells WITH POWER TRANSFER CAPABILITY}

The use of cells with power transfer capability poses new challenges regarding control and modulation strategies, as the existing methods are aimed to balance the operation of cells which have an identical design and operate identically [7][16]. It has been shown in the previous sections that the power transferred by the cells can be controlled by adequate selection of the voltage imbalances $\Delta v_{d c}$ and $\Delta R e\left(v_{a c}\right)$. Consequently, control strategies which provide individual voltage commands for each cell are convenient. A key feature of the potential methods will be therefore whether they use sorting algorithms
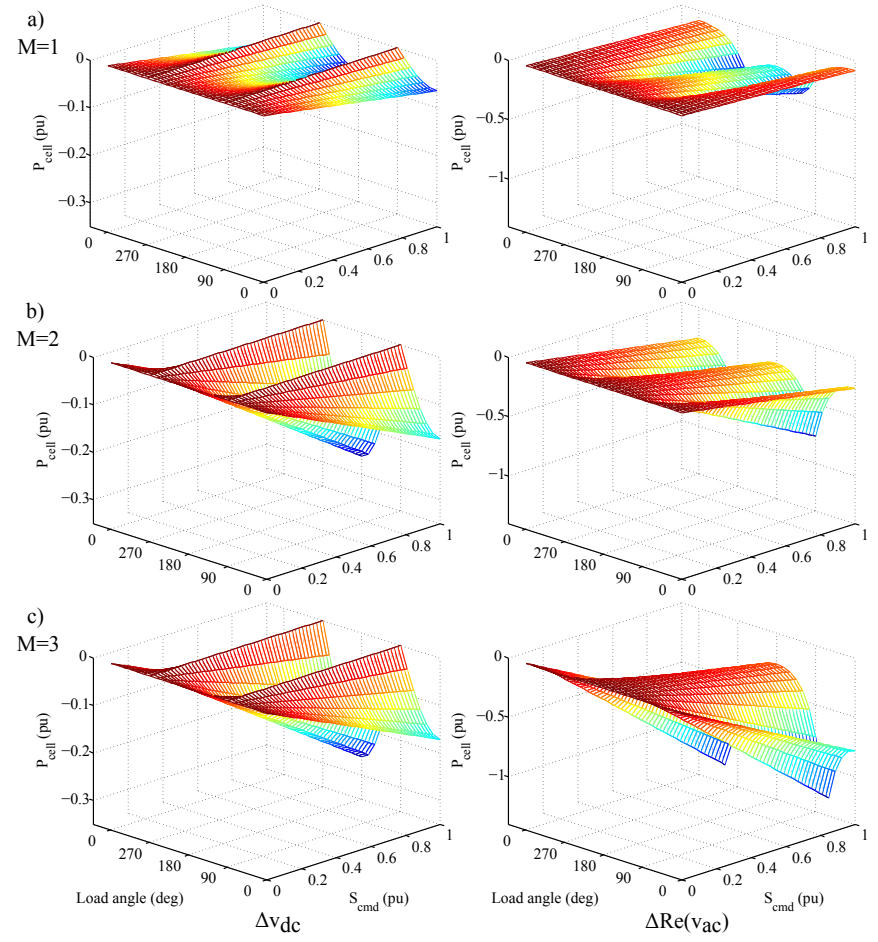

Fig. 9. Maximum power transferred by the cells for a) $M=1$, b) $M=2$ and c) $M=3(N=4)$, as a function of the apparent power and load angle, for the case of DC (left) and AC (right) voltage imbalances.

[12]-[16] or individual balancing [8]-[10]. Two different control strategies are discussed following: A) without explicit selection of $\Delta v_{d c}$ and $\Delta R e\left(v_{a c}\right)$ and $\mathrm{B}$ ) with explicit selection of $\Delta v_{d c}$ and $\Delta R e\left(v_{a c}\right)$. In the discussion following, MMC with symmetric top and bottom arms (Fig.6-d)-e)) is assumed.

\section{A. No explicit selection of $\Delta v_{d c}$ and $\Delta R e\left(v_{a c}\right)$}

Control strategies using sorting algorithms for balancing do not allow to generate individual voltage commands. These strategies still allow to control the power transferred by the cells thanks to the combined action of the circulating current control and sorting algorithm [13]. However, no explicit values for $\Delta v_{d c}$ and $\Delta R e\left(v_{a c}\right)$ are given. This means that for a given power in the AC side and a ratio $R$, it is not guaranteed that the cells will transfer the maximum possible power [19].

\section{B. Explicit selection of $\Delta v_{d c}$ and $\Delta R e\left(v_{a c}\right)$ commands}

It is possible to control the power transferred by the cells by explicitly selecting $\Delta v_{d c}$ and $\Delta R e\left(v_{a c}\right)$. Fig. 10 shows the control strategy proposed in this paper. Its main blocks are discussed following.

The desired active and reactive powers in the $\mathrm{AC}$ side are the inputs to the $A C$ power control block. The resulting voltage commands $v_{d}{ }^{*}$ and $v_{q}{ }^{*}$ are referred to a reference frame aligned with the grid voltage angle $\varphi_{\text {grid }}$. The number of cells transferring power $M$ must be known in advance. Voltage commands block uses (36)-(37) to obtain the AC voltage imbalance required to transfer the cell power. This block operates in a reference fame aligned with the AC current. Similarly, (42)(43) are used to obtain the DC cell voltage imbalance. It was already mentioned that $\mathrm{AC}$ voltage imbalances allow to transfer larger amounts of power compared to DC voltage imbalance. 
If wished, DC voltage unbalance can be disabled, the DC port voltage being in this case evenly split among all the cells. Once the required AC and DC cell voltages are set, (44)-(45) are used to obtain the overall cell voltages [9].

$$
\begin{aligned}
& v_{j x T}^{*}=v_{d c j T}-v_{a c j x T}^{*}-\frac{v_{L x}^{*}}{2 N} \quad j=1: N ; x=u, v, w \\
& v_{j x B}^{*}=v_{d c j B}+v_{a c j x B}-\frac{v_{L x}^{*}}{2 N} \quad j=1: N ; x=u, v, w
\end{aligned}
$$

Circulating current control block controls the circulating current to balance the DC power. An arm balancing control strategy is used to balance the voltage between the upper and lower cell capacitors [13],[15]. Once the references for all the cells are obtained, individual balancing and phase shifted modulation are used to obtain the switches gate signals [9].

TABLE V

Simulation Results. AC Voltage imbalanCE.

\begin{tabular}{c|c|c|c|c|c|c|c|c}
\cline { 2 - 9 } & \multicolumn{2}{c|}{$v_{a c 1 T d}(\mathrm{~V})$} & \multicolumn{2}{c|}{$v_{a c 1 T q}(\mathrm{~V})$} & \multicolumn{2}{c|}{$v_{a c 4 T d}(\mathrm{~V})$} & \multicolumn{2}{c}{$v_{a c 4 T q}(\mathrm{~V})$} \\
\cline { 2 - 9 } & before & after & before & after & before & after & before & after \\
\hline $\begin{array}{c}\mathrm{M}=3 \\
\varphi=0^{\circ}\end{array}$ & -341.1 & -371.8 & -21.75 & -21.75 & -341.1 & -248.13 & -21.75 & -21.75 \\
\hline $\begin{array}{c}\mathrm{M}=2 \\
\varphi=90^{\circ}\end{array}$ & -14.97 & -116.54 & -343.44 & -343.44 & -14.97 & 86.61 & -343.44 & -343.44 \\
\hline
\end{tabular}

\section{Simulation Results}

The operation of a MMC with four cells per arm including cells with power transfer capability has been simulated using Matlab/Simulink. The control block diagram in Fig.10 was used. Only AC voltage imbalance $\Delta R e\left(v_{a c}\right)$ was used, as it allows to transfer more power than DC voltage imbalance.

Fig. 11 shows the response in two different scenarios, with purely active and reactive power in the AC port respectively. The AC power command follows a ramp until $t=0.1 \mathrm{sec}$. At $\mathrm{t}=0.3 \mathrm{sec}$, the cells with power transfer capability start injecting power according to a ramp too, reaching their rated power at $\mathrm{t}=0.4 \mathrm{sec}$. The AC port active and reactive powers are not affected, since they are controlled to be constant. Consequently, power injected by the cells affects to the DC power, which is controlled through the circulating current. Capacitor voltage for the two cells transferring power, $v_{c u 1}$ and $v_{c u 5}$, shows a

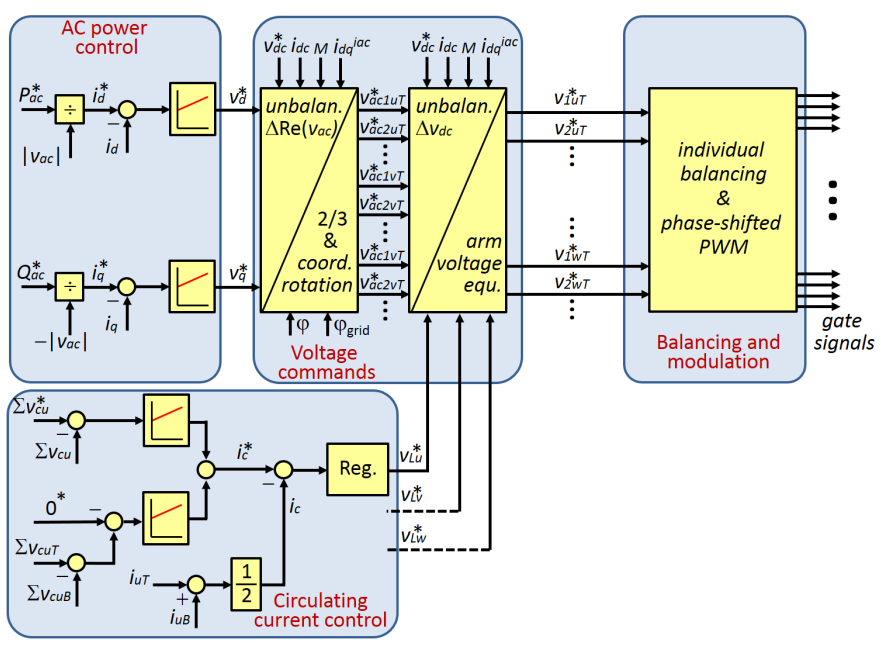

Fig. 10. Proposed MMC control. a) Purely AC active power
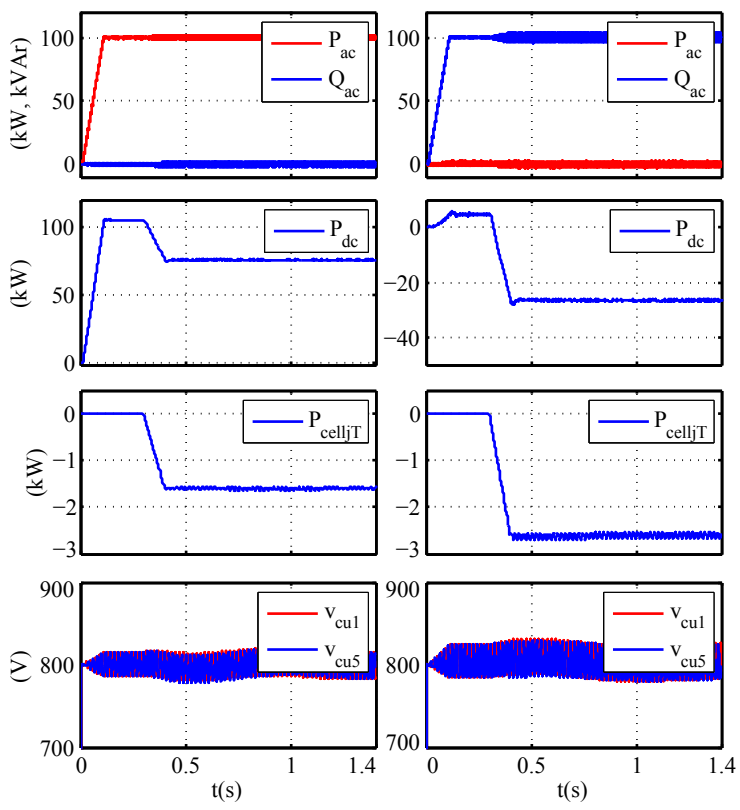

b) Purely AC reactive power
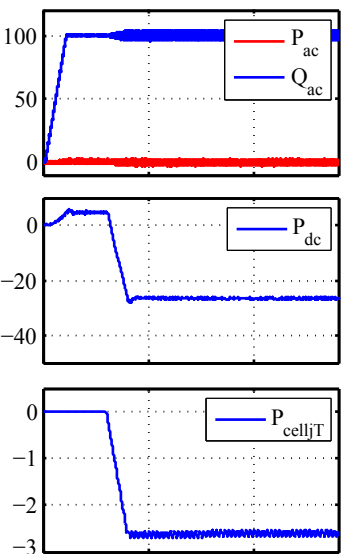

Fig. 11. Simulation results. MMC with four cells per arm $(\mathrm{N}=4)$. From top to bottom: AC active and reactive powers, DC port power, power injected by one cell, capacitor voltages for cells \#1 and \#5 of phase $u$. a) $P_{a c}=100$ $\mathrm{kW}, Q_{a c}=0 \mathrm{kVA}, M=3, M \cdot P_{\text {cell }}=-28.8 \mathrm{~kW}$; b) $P_{a c}=0 \mathrm{~kW}$, $Q_{a c}=100 \mathrm{kVAr}, M=2, M \cdot P_{\text {cell }}=-31.2 \mathrm{~kW}$.

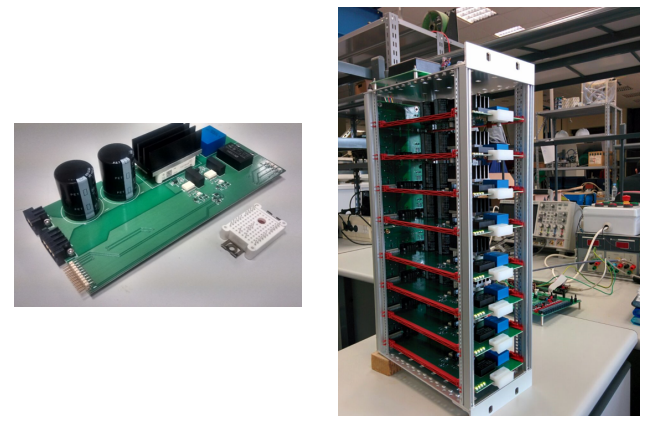

Fig. 12. Eight cell, single-phase, experimental MMC prototype.

small transient disturbance, which is readily controlled by the arm balancing control and the capacitor voltage balancing.

Table V shows the real and imaginary component of the cells $\mathrm{AC}$ voltage vectors for the two cases shown in Fig. 11, without and with cell power transfer. It is noted that real component of the voltage for cells transferring power $v_{a c 1 T d}$, increases, the imaginary component $v_{a c 1 T q}$ remaining constant. Cells which do not inject decrease the real component of their AC voltage $v_{a c 4 T d}$, which is required to maintain the power balance and to provide the required $\mathrm{AC}$ voltage (22).

\section{EXPERIMENTAL RESULTS}

Preliminary experimental verification of the proposed control methods for MMCs using cells with power transfer capability have been realized using an eight cell, single-phase MMC (see Fig.12). The details of the prototype are shown in Table VI. Two cells, one in the top arm and one in the bottom arm, have power transfer capability. DABs are used to transfer power to the cells [22]-[23] (see Fig. 2 c). 


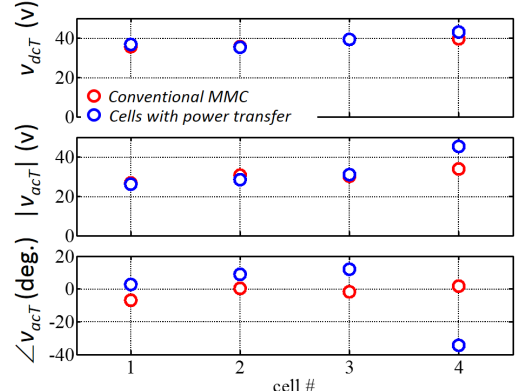

Fig. 13. Experimental results. DC and AC cell voltages for cells \#1 to \#4 when $P_{c e l l}=0.2 P_{a c}$, without explicit selection of $\Delta v_{d c}$ and $\Delta R e\left(v_{a c}\right)$.

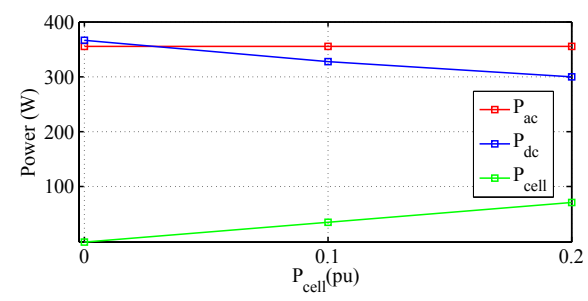

Fig. 14. Experimental results. AC, DC and cell powers for three different cases of $P_{c e l l}$. No explicit selection of $\Delta v_{d c}$ and $\Delta R e\left(v_{a c}\right)$ is implemented.

A control strategy based on a conventional sorting algorithm has been used (see Section VI-A). Fig. 13 shows AC and DC cell voltages when the power transferred by the cells is $P_{\text {cell }}=$ $0.2 p u$. It is observed from this figure that the sorting algorithm responds varying the magnitude and angle of cell AC voltage, the DC voltage being barely affected. Fig. 14 shows DC, AC and cell powers for three different values of $P_{\text {cell }}$. Since the AC power is controlled to be constant, the power transferred by the cells result in a decrease of the power absorbed from the DC port of the MMC.

TABLE VI

EXPERIMENTAL SETUP

\begin{tabular}{c|c}
\hline Power switches & $600 \mathrm{~V} / 23 \mathrm{~A}$ \\
\hline Cell capacitor/Arm inductance & $2000 \mathrm{uF} / 1 \mathrm{mH}$ \\
\hline Cell voltage/DC bus voltage & $80 \mathrm{~V} / 320 \mathrm{~V}$ \\
\hline Switching frequency & $5 \mathrm{Khz}$ \\
\hline
\end{tabular}

\section{CONCLusions}

This paper analyzes the design and control of MMC including cells with power transfer capability. The use of such cells can enhance the functionalities of the MMC, including energy storage integration, connection of low power/low voltage sources/loads, and multiport power converters. However, this requires the development of adequate control strategies, able to cope with the unbalanced operation of the MMC cells.

Mechanisms to control the voltage imbalance needed to transfer power from the cells have been analyzed, as well as the limits of operation, i.e. the maximum power that can be transferred by the cells. A key figure in this regard is the voltage margin between the DC and AC ports of the MMC. A control strategy capable of precisely controlling the power transferred by the cells has been proposed. Simulation and preliminary experimental results have been provided.

\section{REFERENCES}

[1] Gemmell, B.; Dorn, J.; Retzmann, D.; Soerangr, D., "Prospects of multilevel VSC technologies for power transmission," Transmission and Distribution Conference and Exposition, 2008. T\&D. IEEE/PES , vol., no., pp.1,16, 21-24 April 2008, Chicago, IL, USA

[2] Xiao-Ping Zhang, Christian Rehtanz, Bikash Pal, Flexible AC Transmission Systems: Modeling and Control. Springer, 2012.

[3] J. Rodriguez, J.-S. Lai, and F. Z. Peng, "Multilevel inverters: A survey of topologies, controls, and applications," IEEE Trans. Ind. Electron., vol. 49, no. 4, pp. 724-738, Aug. 2002.

[4] A. Lesnicar, and R. Marquardt: An Innovative Modular Multilevel Converter Topology Suitable for a Wide Power Range, IEEE PowerTech Conference, Bologna, Italy, June 23-26, 2003

[5] M. Glinka and R. Marquardt: A New AC/AC Multilevel Converter Family, IEEE Trans. on Ind. Electron., vol. 52, no. 3, June 2005

[6] A. Lesnicar, and R. Marquardt: A new modular voltage source inverter topology, EPE'03, Toulouse, France, September 2-4, 2003

[7] Rohner, S.; Bernet, S.; Hiller, M.; Sommer, R.; , "Analysis and Simulation of a $6 \mathrm{kV}, 6$ MVA Modular Multilevel Converter," IECON'09, pp.225-230, 3-5 Nov. 2009, Porto, PT

[8] Akagi, H., "Classification, Terminology, and Application of the Modular Multilevel Cascade Converter (MMCC)," Power Electron., IEEE Trans. on , vol.26, no.11, pp.3119,3130, Nov. 2011

[9] Hagiwara, M.; Akagi, H.; , "Control and Experiment of PulsewidthModulated Modular Multilevel Converters," Power Electron., IEEE Trans. on, vol.24, no.7, pp.1737-1746, July 2009

[10] Hagiwara, M.; Maeda, R.; Akagi, H.; , "Control and Analysis of the Modular Multilevel Cascade Converter Based on Double-Star ChopperCells (MMCC-DSCC)," Power Electron., IEEE Trans. on , vol.26, no.6, pp.1649-1658, June 2011

[11] Li, Wei; Gregoire, Luc-Andre; Belanger, Jean., "Control and Performance of a Modular Multilevel Converter System", Conference on Power Systems (CIGRE), Canada, 6-8 Sept. 2011

[12] Perez, M.A.; Lizana F, R.; Rodriguez, J., "Decoupled current control of modular multilevel converter for HVDC applications," IEEE ISIE'12, pp.1979,1984, 28-31 May 2012, Hangzhou, CHN

[13] Jae-Jung Jung; Hak-Jun Lee; Seung-Ki Sul, "Control strategy for improved dynamic performance of variable-speed drives with the Modular Multilevel Converter," IEEE ECCE'13, pp.1481,1488, 15-19 Sept. 2013, Denver, CO, USA

[14] Peftitsis, D.; Tolstoy, G.; Antonopoulos, A.; Rabkowski, J.; Lim, JangKwon; Bakowski, M.; Angquist, L.; Nee, H-P, "High-power modular multilevel converters with SiC JFETs," IEEE ECCE'10, pp.2148,2155, 12-16 Sept. 2010, Atlanta, GA, USA

[15] Antonopoulos, A.; Angquist, L.; Nee, H.-P.; , "On dynamics and voltage control of the Modular Multilevel Converter," EPE'09, pp.1-10, 8-10 Sept. 2009, Barcelona,ESP

[16] Saeedifard, M.; Iravani, R., "Dynamic P erformance of a Modular Multilevel Back-to-Back HVDC System," Power Delivery, IEEE Trans. on , vol.25, no.4, pp.2903,2912, Oct. 2010

[17] Vasiladiotis, M.; Rufer, A., "Analysis and Control of Modular Multilevel Converters With Integrated Battery Energy Storage," Power Electron., IEEE Trans. on , vol.30, no.1, pp.163,175, Jan. 2015

[18] Hagiwara, M.; Hasegawa, I.; Akagi, H., "Start-Up and Low-Speed Operation of an Electric Motor Driven by a Modular Multilevel Cascade Inverter,” Ind. Appl., IEEE Trans. on , vol.49, no.4, pp.1556,1565, JulyAug. 2013

[19] Briz, F.; Lopez, M.; Zapico, A.; Rodriguez, A.; Diaz-Reigosa, D., "Operation and Control of MMCs Using Cells with Power Transfer Capability," IEEE APEC'15, 15-19 March 2015, Charlotte, NC, USA

[20] Briz, F.; Lopez, M.; Rodriguez, A.; Zapico, A.; Arias, M.; Diaz-Reigosa, D., "MMC based SST", 13th International Conference on Industrial Informatics (INDIN), 22-24 July 2015, Cambridge, UK

[21] Lopez, M.; Rodriguez, A.; Blanco, E.; Saeed, M.; Martinez, A.; Briz, F., "Design and Implementation of the Control of an MMC-Based Solid State Transformer", 13th International Conference on Industrial Informatics (INDIN), 22-24 July 2015, Cambridge, UK

[22] De Doncker, R.W.A.A.; Divan, D.M.; Kheraluwala, M.H., "A threephase soft-switched high-power-density DC/DC converter for highpower applications," Ind. Appl., IEEE Trans. on , vol.27, no.1, pp.63,73, $\mathrm{Jan} / \mathrm{Feb} 1991$

[23] Rodriguez, A.; Vazquez, A.; Lamar, D.G.; Hernando, M.M.; Sebastian, J., "Different Purpose Design Strategies and Techniques to Improve the Performance of a Dual Active Bridge With Phase-Shift Control," Power Electron., IEEE Trans. on, vol.30, no.2, pp.790,804, Feb. 2015 